\title{
Observations and analysis of polar stratospheric clouds detected by POAM III and SAGE III during the SOLVE II/VINTERSOL campaign in the 2002/2003 Northern Hemisphere winter
}

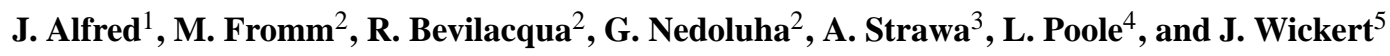 \\ ${ }^{1}$ Computational Physics Inc., Springfield VA, USA \\ ${ }^{2}$ Naval Research Lab, Remote Sensing Division, Washington D.C., USA \\ ${ }^{3}$ NASA Ames Research Center, Atmospheric Physics Branch, Moffett Field CA, USA \\ ${ }^{4}$ Science Systems \& Applications Inc., Hampton VA, USA \\ ${ }^{5}$ GeoForschungsZentrum, Dept. Geodesy and Remote Sensing, Potsdam, Germany
}

Received: 18 September 2006 - Published in Atmos. Chem. Phys. Discuss.: 16 November 2006

Revised: 15 March 2007 - Accepted: 5 April 2007 - Published: 2 May 2007

\begin{abstract}
The Polar Ozone and Aerosol Measurement and Stratospheric Aerosol and Gas Experiment instruments both observed high numbers of polar stratospheric clouds (PSCs) in the polar region during the second SAGE Ozone Loss and Validation (SOLVE II) and Validation of INTERnational Satellites and Study of Ozone Loss (VINTERSOL) campaign, conducted during the 2002/2003 Northern Hemisphere winter. Between 15 November 2002 (14 November 2002) and 18 March 2003 (21 March 2003) SAGE (POAM) observed 122 (151) aerosol extinction profiles containing PSCs. PSCs were observed on an almost daily basis, from early December through 15 January, in both instruments. No PSCs were observed from either instrument from 15 January until 4 February, and from then only sparingly in three periods in mid- and late February and mid-March. In early December, PSCs were observed in the potential temperature range from roughly $375 \mathrm{~K}$ to $750 \mathrm{~K}$. Throughout December the top of this range decreases to near $600 \mathrm{~K}$. In February and March, PSC observations were primarily constrained to potential temperatures below $500 \mathrm{~K}$. The PSC observation frequency as a function of ambient temperature relative to the nitric acid-trihydrate saturation point (using a nitric acid profile prior to denitrification) was used to infer irreversible denitrification. By late December 38\% denitrification was inferred at both the $400-475 \mathrm{~K}$ and $475-550 \mathrm{~K}$ potential temperature ranges. By early January extensive levels of denitrification near $80 \%$ were inferred at both potential temperature ranges, and the air remained denitrified at least through early March.
\end{abstract}

Correspondence to: J. Alfred

(alfred@cpi.com)

\section{Introduction}

The second SAGE Ozone Loss and Validation (SOLVE II) campaign was a multi-platform measurement campaign during the 2002/2003 Northern Hemisphere (NH) winter in the polar region. The SOLVE II/VINTERSOL campaign was conducted in close collaboration with the Validation of INTERnational Satellites and Ozone Loss (VINTERSOL) campaign. The primary aim of SOLVE II/VINTERSOL was to validate the Stratospheric Aerosol and Gas Experiment III (SAGE) instrument by investigating the processes surrounding stratospheric ozone loss in the polar region. Given the important - and as yet not fully understood - role of polar stratospheric clouds (PSCs) (a SAGE III measurement product) in the photochemistry of polar ozone, a further understanding of PSCs and their role in the interactions of chlorine and nitrogen reservoir species was another main scientific objective of the SOLVE II campaign (http://cloud1.arc. nasa.gov/solveii/science.html).

PSCs are currently known to exist in three main phases which are categorized as Type I and Type II (Poole and McCormick, 1988), with Type I PSCs subdivided into Type IA and Type IB (Browell et al., 1990). Type IA PSCs are thought to be composed of nitric-acid trihydrate (NAT) and/or nitricacid dihydrate (NAD). NAT particles condense at a temperature of $\sim 195 \mathrm{~K}$ under normal ambient stratospheric conditions at an altitude of $20 \mathrm{~km}$ and can grow to sufficient sizes (up to $20 \mu \mathrm{m}$ (Fahey et al., 2001)) such that they can sediment to lower altitudes. This sedimentation process is referred to as irreversible denitrification. Type IB PSCs contain particles that are smaller $(0.08-0.3 \mu \mathrm{m})$ than those in Type IA and are composed of a liquid mixture of the

Published by Copernicus GmbH on behalf of the European Geosciences Union. 
background sulfate aerosols swelling with the absorption of water vapor and nitric acid into a super-cooled ternary solution (STS) and form near temperatures of $191 \mathrm{~K}$ at $20 \mathrm{~km}$ under normal stratospheric ambient conditions. Type IB PSCs do not grow to sufficient sizes to undergo substantial sedimentation, thus do not significantly enhance the process of irreversible denitrification, however they do remove gasphase $\mathrm{HNO}_{3}$ and cause temporary denitrification (further references to the term denitrification refer specifically to irreversible denitrification). Type II PSCs are composed of ice particles and form at $\sim 188 \mathrm{~K}$ at $20 \mathrm{~km}$ under normal ambient stratospheric conditions. Type II PSCs grow to sufficiently large sizes to sediment to lower altitudes and dehydrate the stratosphere. PSCs are currently thought to affect the photochemistry of ozone in two ways: i) as direct sites for heterogeneous interactions between chlorine species and ozone resulting in ozone loss; ii) through the process of sedimentation of PSC particles resulting in the removal of nitrogen species which normally combine with and sequester chlorine. The latter of these two processes is believed to enhance ozone loss by up to $30 \%$ (Tabazadeh et al., 2000). Because these two processes are the main factors governing photochemical ozone loss, a further understanding of PSCs and the nitrogen budget is critical to understanding ozone loss.

The Naval Research Laboratory's Polar Ozone and Aerosol Measurement III (POAM) is a space-borne solar occultation instrument similar in scientific capabilities and measurement coverage to SAGE. It was fully operational during the 2002/03 NH winter, and was a participant in the SOLVE II/VINTERSOL campaign (as it was during the SOLVE/THESEO campaign conducted in 2000). In this paper we apply the Unified PSC detection methodology (Fromm et al., 2003) to both SAGE (Thomason and Taha, 2003) and POAM one-micron aerosol-extinction measurements to detect PSCs. The Unified PSC detection is an established methodology developed specifically as an instrument independent algorithm for detection of PSCs from solar occultation aerosol-extinction measurements. The technique has previously been applied to POAM (Fromm et al., 2003; Bevilacqua et al., 2002), SAM II and SAGE II data (Fromm et al., 2003). However, this analysis represents the first use of the technique with SAGE III data. First, we compare the resultant POAM and SAGE III databases during the SOLVE II/VINTERSOL winter. Next, we present an overview of the evolution of PSCs using measurements from both instruments and view this in reference to the meteorology of the SOLVE II/VINTERSOL winter and the climatology of previous NH PSC seasons. We then combine the SAGE and POAM PSC observations, and use the combined dataset to quantify PSC occurrence temperatures and their evolution as the season progresses. Expanding on the technique developed by Bevilacqua et al. (2002), PSC occurrence temperatures are used to infer denitrification over the course of the season.

\section{POAM/SAGE instruments and measurement sam- pling}

POAM is a satellite-based nine-channel visible/near infrared photometer for making measurements of ozone, aerosol extinction, water vapor and nitrogen dioxide using the solar occultation technique (Lucke et al., 1999). POAM was launched on board the Satellite Pour l'Observation de la Terre (SPOT 4) satellite on 23 March 1998 in a sunsynchronous polar orbit with an inclination of $98.7^{\circ}$ and 10:30 LT descending node. SAGE is also a satellite-based visible/near infrared solar occultation instrument and measures the same atmospheric constituents as POAM. However, unlike POAM, which uses individual filters, the SAGE instrument uses a grating spectrometer and an 800-element linear CCD detector to provide continuous spectral coverage from 280 to $1040 \mathrm{~nm}$, with an additional photodiode at $1550 \mathrm{~nm}$ for measuring aerosol extinction (NASA, 2002). SAGE was launched on board Meteor-3M spacecraft on 10 December 2001 in a sun-synchronous polar orbit with an ascending node time of approximately 09:00 LT. SAGE was fully operational during the SOLVE II/VINTERSOL campaign.

As with all satellite-based solar occultation instruments, both POAM and SAGE make measurements during satellite sunrises and sunsets (the SAGE instrument has increased sampling with limb scattering measurements, but here we only use the solar occultation measurements). This yields two measurements per orbit giving 14-15 measurements in each hemisphere on a daily basis for each instrument. As SPOT 4 has a daytime crossing of the equator in the descending node, and Meteor-3M has a daytime crossing of the equator in the ascending node, with respect to the satellite, $\mathrm{NH}$ measurements are made at sunrise with POAM and sunset with SAGE. This leads to an inherent time difference in measurements even when both SAGE and POAM are sampling similar latitudes. Both instruments are on board satellites in sun-synchronous polar orbits, thus they sample around a circle of latitude on a given day with a longitude spacing of approximately $25^{\circ}$, with the measurement latitude changing gradually in an annually periodic cycle. Because the Meteor3M satellite has a 09:00 LT equator crossing and the SPOT 4 has a 10:30 LT equator crossing, SAGE generally samples higher latitudes than POAM in the NH. Figure 1 shows the measurement latitude of both the SAGE and POAM instruments as a function of time throughout the 2002/2003 NH winter, with the SAGE latitudinal coverage shown in black, and that of POAM in red. Given the latitudinal range of coverage for the SAGE and POAM instruments, both are very well suited to observe PSCs in the NH. Combining measurements from the two instruments allows for a wider range of coverage than would be available from one instrument only.

Figure 2 shows the equivalent latitude on the $500 \mathrm{~K}$ potential temperature surface (approximately $20 \mathrm{~km}$ ) for all of the SAGE and POAM NH measurements during the SOLVE 


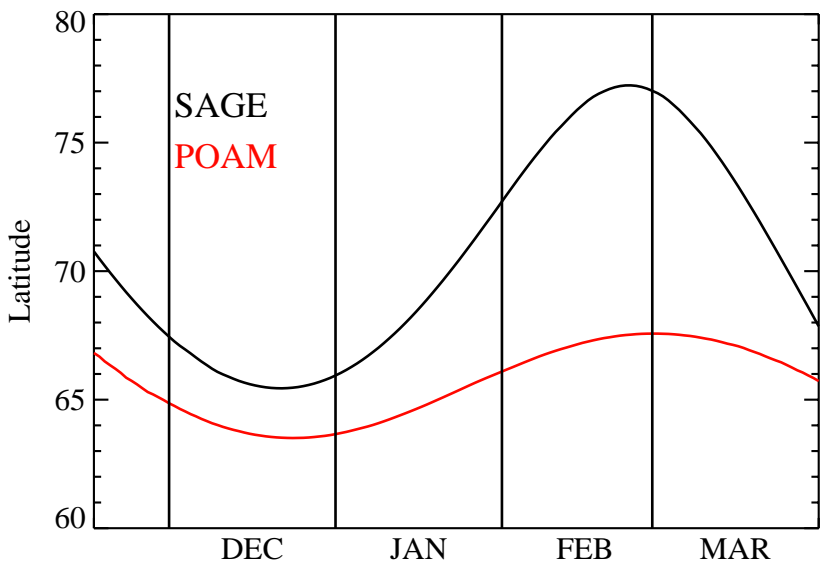

Fig. 1. SAGE and POAM measurement latitudes for the 2002/2003 NH winter. The black curve denotes the SAGE measurement latitude, and the red curve denotes POAM. Both instruments sample a complete circle of longitude per day making roughly 14 measurements.

II/VINTERSOL winter. Equivalent latitude is a vortex-based coordinate system based on Ertel's potential vorticity (EPV). For this analysis EPV values were obtained from the daily values (12:00 UTC) from the United Kingdom Meteorological Office (MetOffice) (Swinbank and O'Neill, 1994) analysis, and interpolated in latitude, longitude, altitude and time to the measurement locations of each instrument throughout the winter. On the figure, the polar vortex region is denoted with curves indicating the equatorward, middle and poleward edges as determined by the vortex discrimination algorithm developed by Nash et al. (1996) (further references to the vortex edge will refer to the middle edge). Figure 2 indicates that both SAGE and POAM sample air inside, outside and on the edge of the polar vortex on the $500 \mathrm{~K}$ surface every day from November through April. As most PSCs occur inside the polar vortex, the extensive coverage provided by combining the POAM and SAGE measurements should provide a fair characterization of the morphology of PSCs during the winter.

To illustrate the temperatures obtained during the SOLVE II/VINTERSOL winter, Fig. 3 shows a time series of the minimum temperature $\left(\mathrm{T}_{\min }\right)$ with respect to the NAT condensation temperature $\left(\mathrm{T}_{\mathrm{NAT}}\right)$ from November through April. For the calculation of $\mathrm{T}_{\mathrm{NAT}}$ we use the formulation given in Hanson and Mauersburger (1988) assuming constant mixing ratios of water vapor and nitric acid of 6 ppmv and 9 ppbv respectively and the minima were calculated over the 150 to $10 \mathrm{hPa}$ range. Temperatures were obtained from the MetOffice gridded analysis. Figure 3 shows the vortex $\mathrm{T}_{\min }$, as well as $T_{\min }$ in $a \pm 2^{\circ}$ latitude band around the SAGE and POAM measurement latitudes. The range of vortex $\mathrm{T}_{\min }$ from 1994 to 2004 is also shown, as a reference. The early 2002/2003 winter was unusually cold, with a major warming in lateJanuary. Temperatures were cold again in early-February,

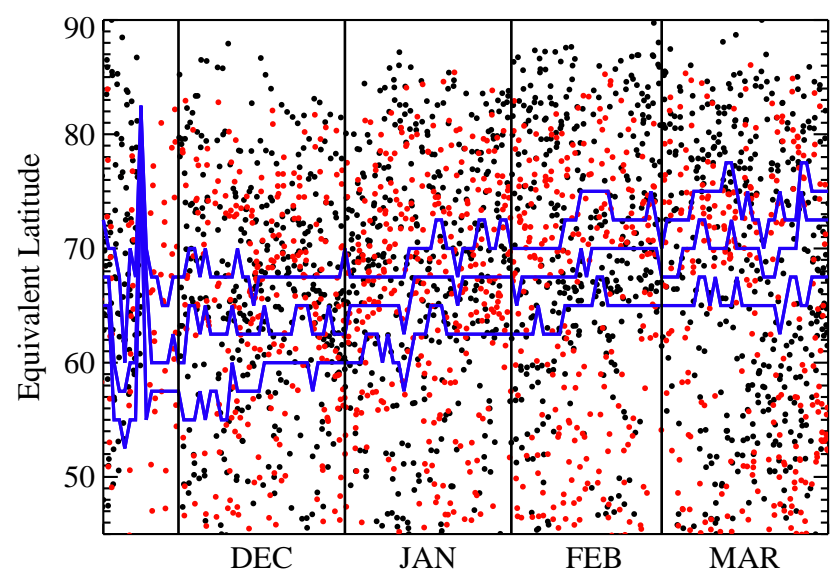

Fig. 2. The equivalent latitude of each SAGE (black symbols) and POAM (red symbols) measurement interpolated to the $500 \mathrm{~K}$ theta surface. The Nash vortex edge is shown in the three blue curves, with the upper, middle and lower curves representing the inner, middle and outer vortex edges respectively.

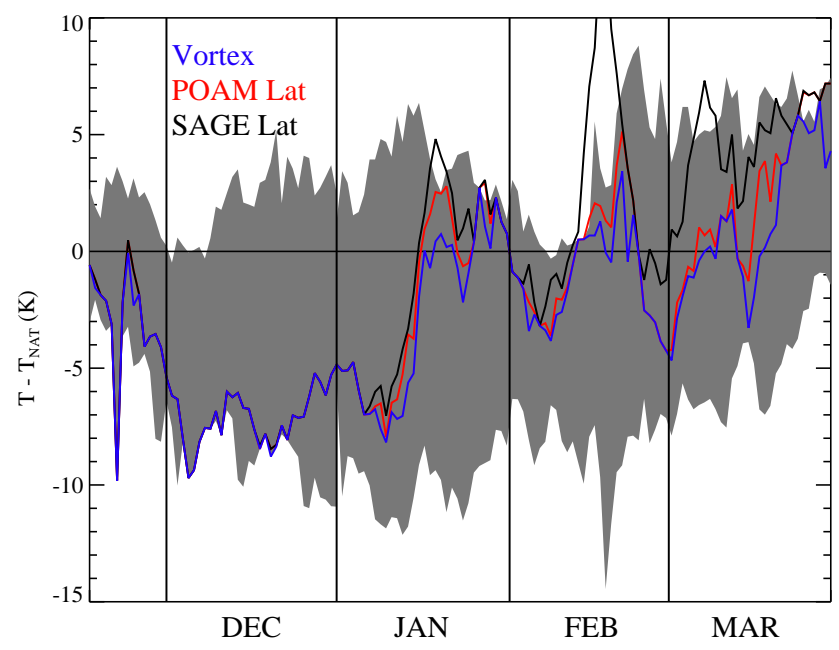

Fig. 3. Time series of the minimum T-Tnat over the $10-150 \mathrm{hPa}$ range for the $2002 / 2003 \mathrm{NH}$ winter. The blue curve denotes the minimum temperature over the entire vortex, the black curve over a two-degree latitude band around the SAGE measurement latitude, and the red curve over a two-degree latitude band around the POAM measurement latitude. The shaded grey area denotes the range of vortex-wide minima over the 1994 to 2004 winters.

and late-February/early-March with a near major warming in mid-February and early-March (Naujokat and Grunnow, 2003; Manney et al., 2005). All of these features are clearly illustrated in Fig. 3. From the beginning of December until the late-January warming, minimum vortex temperatures were persistently sub- $\mathrm{T}_{\mathrm{NAT}}$. In fact, in the first half of December the 2002/2003 vortex minimum temperatures were the coldest obtained in the 1994-2004 period. Both SAGE and POAM sample at or near the coldest air at this time as both are only separated by roughly 2 degrees of latitude. As 


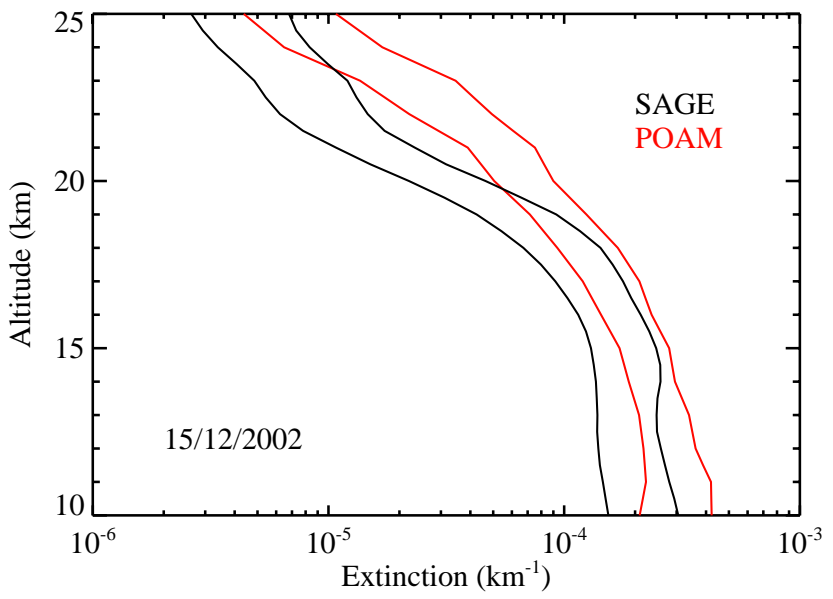

Fig. 4. The POAM BG extinction, and three-sigma threshold are shown in red. Those of SAGE are shown in black. The BG and three-sigma threshold are interpolated to 15 December 2002.

the SAGE and POAM measurement latitudes begin to separate beginning in early January (see Fig. 1) the POAM and SAGE temperature sampling also begins to separate. Interestingly, however, although SAGE measures at increasingly higher latitudes than POAM, POAM generally samples closer to the coldest vortex air, suggesting that the cold pool was offset from the North Pole during this period. After the January warming but before the mid-February warming minimum temperatures generally fluctuated near $\mathrm{T}_{\mathrm{NAT}}$. After the mid-February warming the vortex then again experienced a ten-to-twelve day period of temperatures below $\mathrm{T}_{\mathrm{NAT}}$ with another short sub- $\mathrm{T}_{\mathrm{NAT}}$ period in early-March. This sub$\mathrm{T}_{\mathrm{NAT}}$ air was sampled by POAM (which generally sampled the coldest vortex air during these periods), but not by SAGE, again suggesting that the cold pool was offset from the North Pole. In fact, except for two very brief periods in early and late February, after the mid-January warming SAGE did not sample sub- $\mathrm{T}_{\mathrm{NAT}}$ air for the duration of the winter.

\section{Overview of SAGE and POAM PSC observations dur- ing the 2002/2003 winter}

\subsection{PSC detection}

PSC detection was performed using the unified detection algorithm developed by Fromm et al. (2003). For both POAM and SAGE, the algorithm uses measured aerosol extinction at $1 \mu \mathrm{m}$ (POAM: channel 9 at $1.018 \mu \mathrm{m}$, and SAGE: $1.021 \mu \mathrm{m})$. The algorithm objectively determines a reference background modal value (BG) for aerosol extinction, and a standard deviation (sigma) about the BG for each instrument independently. The BG and sigma are calculated assuming that in the presence of PSCs the non-PSC aerosol extinction distribution is quasi-Gaussian, with PSC extinctions form- ing a tail of high extinctions. The BG and sigma are determined from this quasi-Gaussian mode, for both inside and outside of the polar vortex air masses. The BG and sigma are calculated in 30-day increments, and interpolated to a daily grid. PSC detection is conducted by delineating each profile, at each individual altitude, with respect to the polar vortex edge. The extinction at each altitude in the profile is then compared to the appropriate in- or out-of-vortex BG and sigma values for the day of the measurement. Perturbations in extinction are defined in multiples of sigma. A PSC is presumed to exist when the measured aerosol extinction exceeds the background level by $>3$ sigma, and the ambient temperature from the co-located MetOffice grid (as described in Sect. 2, for the collocation to the MetOffice EPV field) is less than five Kelvin above $\mathrm{T}_{\mathrm{NAT}}$, calculated assuming a constant water vapor and $\mathrm{HNO}_{3}$ content of $6 \mathrm{ppmv}$ and $9 \mathrm{ppbv}$, respectively.

Figure 4 shows the BG and three-sigma extinction thresholds, inside the vortex and interpolated to 15 December 2002, for both SAGE and POAM instruments, as a function of altitude. This shows that there is a clear disagreement at some altitudes between the POAM and SAGE invortex background and 3-sigma aerosol extinction levels during the 2002/2003 winter. We have found that this level of disagreement is present in the vortex in all subsequent $\mathrm{NH}$ winter seasons. Differences in out-of-vortex BGs between the two instruments are less pronounced. Russell et al. (2005) show the mean ratio of SAGE/POAM out-ofvortex extinction measurements of 0.68 at $20 \mathrm{~km}$, in January 2003. The out-of-vortex difference also does not vary over the season. The characterization and possible origin of the large POAM/SAGE bias in background aerosol extinction in the vortex exhibited in Fig. 4 is discussed in detail by Randall et al. $(2007)^{1}$. The difference is time-varying, with the SAGE extinction continuing to decrease to much lower values than POAM as the season progresses. The very low values measured by SAGE may be caused by aerosol cleansing inside the vortex caused by descent of low aerosol-containing air from higher altitudes and sedimentation of pre-existing PSCs. The effect of aerosol cleansing in the POAM measurements is less pronounced. We also note that Russell et al. (2004) have compared SAGE and POAM aerosol optical depth (AOD) with the NASA Ames Airborne Tracking Sunphotometer (AATS-14), which compares the SAGE and POAM measurements to an independent measurement. Russell et al. compare AATS-14 AOD to four SAGE and six POAM near-coincident (the SAGE and POAM profiles were not coincident with one another) profiles in January, 2003. POAM and SAGE AOD were determined from direct integration of the extinction profiles. Russell et al. show that the AATS-14 one-micron optical-depth had a mean difference

\footnotetext{
${ }^{1}$ Randall, C. E., Lumpe, J. D., Zawodny, J., Bevilacqua, R. M., et al.: Intercomparison of aerosols from solar occultation instruments, in preparation, 2007.
} 
with respect to SAGE ([SAGE - AATS-14]/AATS-14) of $-59.3 \%$, but only $-30 \%$ difference with respect to POAM. On the other hand, an analysis by Thomason et al. (2006) concludes that SAGE aerosol extinction values inside the vortex are not biased low, and that low extinction values are a product of geophysical process.

While the origin of the POAM/SAGE background aerosol extinction differences is beyond the scope of this paper, the implications of this large bias for PSC detection with the two instruments must be understood because an important goal of this paper is to combine the two data sets to obtain more complete coverage of the polar vortex. In order to do this, in Fig. 5 we plot the SAGE and POAM extinction measurements (black and red circles respectively) at $20 \mathrm{~km}$ as a function of measurement temperature, inside the polar vortex in December, 2002, as well as the POAM and SAGE PSC extinction threshold (i.e. BG + 3 sigma) interpolated to 15 December 2002. In the warm-temperature/lowaerosol extinction regime, the bias indicated in Fig. 4 is clearly seen, yet in the low-temperature/high-aerosol extinction regime (PSC conditions) both the SAGE and POAM data sets are in very good agreement. However, at temperatures between $0 \mathrm{~K}<\mathrm{T}-\mathrm{T}_{\mathrm{NAT}}<10 \mathrm{~K}$ the SAGE aerosol extinction values tend to increase with decreasing temperature while those of POAM remain flat such that at relative temperatures $<0 \mathrm{~K}$ the two data sets agree very well, with both suggesting PSC activation in the temperature region of $-3 \mathrm{~K}<\mathrm{T}_{\mathrm{NAT}}<+3 \mathrm{~K}$. Thus, the POAM/SAGE bias indicated in Fig. 4 is a low aerosol extinction issue. The cause is not clear; however, we note that in such a low aerosol extinction environment, small systematic radiometric or pointing errors can result in large fractional aerosol extinction errors. As we have already noted, the SAGE data shown in Fig. 5 do indicate a slow increase in aerosol extinction in the $0 \mathrm{~K}<\mathrm{T}-\mathrm{T}_{\mathrm{NAT}}<10 \mathrm{~K}$ range. This may be the result of swelling of sulfate particles as the ambient temperature decreases (Carslaw et al., 1994). Of course, in that case, the point at which the aerosol growth is sufficiently large to be designated a PSC is somewhat arbitrary. It is not unreasonable to assume that the modest enhancements in aerosol extinction just above the $\mathrm{T}_{\mathrm{NAT}}$ temperature observed in the SAGE data set is the result of the beginning of PSC activity that POAM does not detect. These small aerosol extinction enhancement PSCs would be detected in the SAGE data set. They would not be detected in the POAM data set, thus the lower SAGE threshold would lead to more PSCs being detected by SAGE than by POAM. It is evident that, in developing a consistent combined data set we therefore cannot use the instrument-specific PSC threshold values. If we are to use a common threshold value, we must then compensate for any bias between the two instruments. Because the BG of each instrument is interpolated to a daily value, we can calculate the average POAM-SAGE bias - the difference between the POAM and SAGE BG - on a daily basis. To compensate for this bias, we add the POAM-SAGE bias to the SAGE

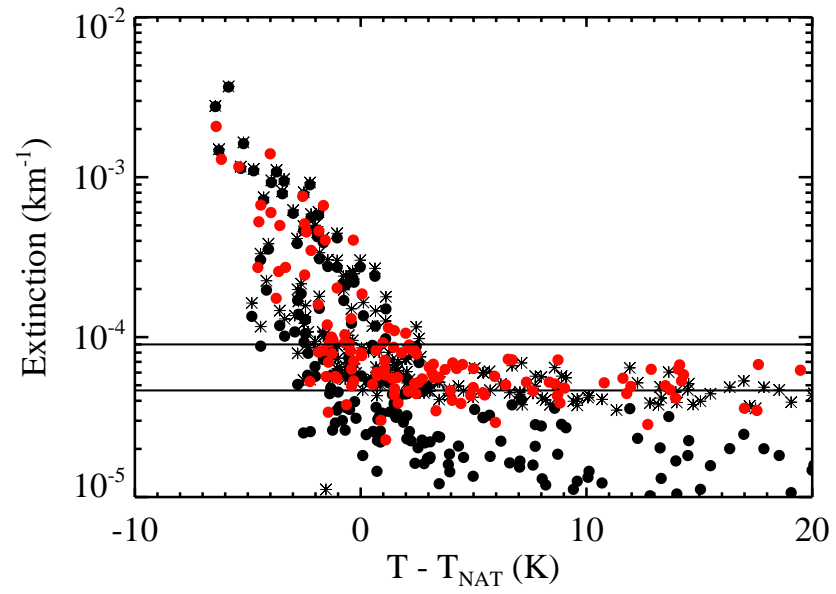

Fig. 5. SAGE (black circles) and POAM (red circles) one-micron extinction measurements at $20 \mathrm{~km}$ inside the polar vortex in December 2002. SAGE bias-compensated extinctions are shown in black asterisks. The two solid black lines indicate the SAGE (lower) and POAM (upper) extinction threshold (i.e. BG + 3 sigma) for PSC detection interpolated to 15 December 2002.

data. In Fig. 5 we also show the bias-compensated SAGE data set (shown in black asterisks). The bias-compensated SAGE data now agree very well with the POAM data in the $0 \mathrm{~K}<\mathrm{T}-\mathrm{T}_{\mathrm{NAT}}<10 \mathrm{~K}$ temperature range while the very good agreement at the low temperature region remains.

As an example to illustrate the combined POAM/SAGE PSC detection approach developed here, in Fig. 6, we show the SAGE (without the bias-compensation) and POAM onemicron extinction profiles for a pair of coincident (separated by $3 \mathrm{~h}$ in time and $243 \mathrm{~km}$ in space) measurements conducted on 16 December 2002, in which a PSC was indicated for both POAM and SAGE. The POAM in-vortex BG and the threesigma extinction profiles (which are used as the PSC extinction threshold for both the POAM and SAGE data sets) interpolated 16 December 2002 are also shown. It should be noted that, although the aerosol extinction is shown as a function of potential temperature, the PSC detection algorithm is conducted on the altitude grid native to the POAM and SAGE datasets (POAM data are on an integer one-kilometer grid, while SAGE data are on a half-kilometer grid). The measurements agree very well, indicating a layer of enhanced extinction which exceeds the PSC threshold (and is therefore designated a PSC) from 460 to $575 \mathrm{~K}$. The altitude of the peak of the aerosol extinction is also in good agreement in both measurements. Differences in the shapes of the PSC measurements could be attributable to either the different viewing geometries between SAGE and POAM, or the evolution of the PSC over the span of three hours. Outside of the PSC regime where aerosol extinction is lower, the POAM aerosol extinction values tend to be larger than those of SAGE which is in agreement with Fig. 5. The temperature screen in the PSC detection algorithm precluded the POAM measurements below $14 \mathrm{~km}$ from being a PSC. 


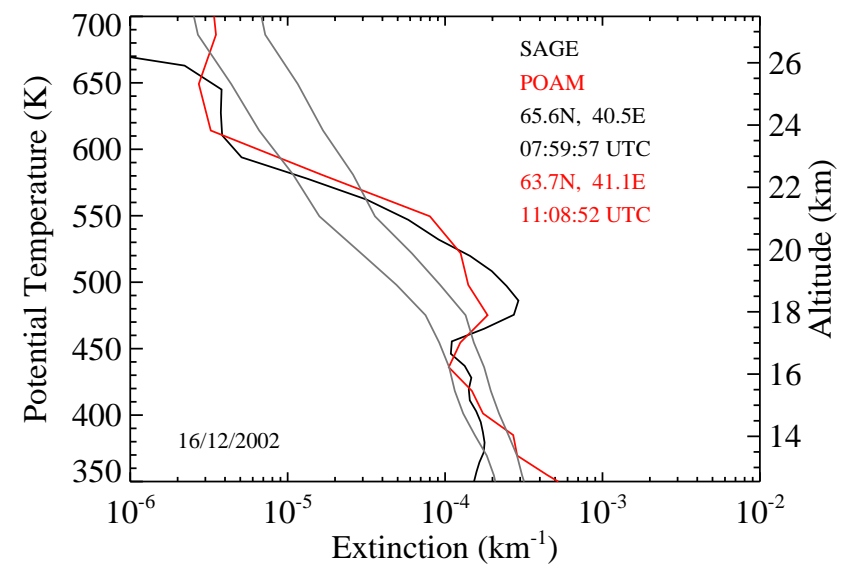

Fig. 6. SAGE and POAM one-micron extinction profiles of an observed PSC on 16 December 2002, plotted as a function of potential temperature (altitude is shown on the right axis for reference). The black curve denotes the SAGE profile, and the red curve denotes the POAM profile. The two measurements were separated by roughly $240 \mathrm{~km}$ in space and three hours in time, and likely depict the same PSC.

As a more comprehensive test of our combined POAM/SAGE PSC detection approach in Fig. 7 we show the PSC observation probability as a function of ambient temperature with respect to $\mathrm{T}_{\mathrm{NAT}}$ for the $400-475 \mathrm{~K}$ potential temperature range, from 1-10 January 2003 for SAGE and POAM separately (black and red curves, respectively). For these calculations the data within the given time-range from each instrument were binned into two-Kelvin temperature bins. The occurrence probability is defined as the number of observed PSCs inside the vortex divided by the total number of observations, inside the vortex, within each bin. The temperature bins, while being two-Kelvin wide, were calculated in overlapping half-Kelvin intervals to smooth the data, thus, each datapoint represents the probability for PSCs at temperatures within $\pm 1 \mathrm{~K}$ of the indicated temperature. A probability was only calculated if the number of measurements within a given temperature bin was five or greater. The one-sigma uncertainty level is plotted for both instruments in the dashed curves. To calculate the one-sigma uncertainty, we assume the PSC probability in a given bin follows a binomial distribution. The standard deviation of a binomial distribution is given by Bevington and Robinson (1992)

$\sigma=\frac{\sqrt{N p(1-p)}}{N}$

where $\sigma$ is the calculated uncertainty for a given temperature bin, $N$ is the number of observations in a given temperature bin and $p$ is the PSC probability in a given temperature bin. Note that the SAGE uncertainties are lower than those of POAM as SAGE generally yields twice the number of observations due to its half-kilometer binning, compared to the one-kilometer binning of POAM. The SAGE and POAM

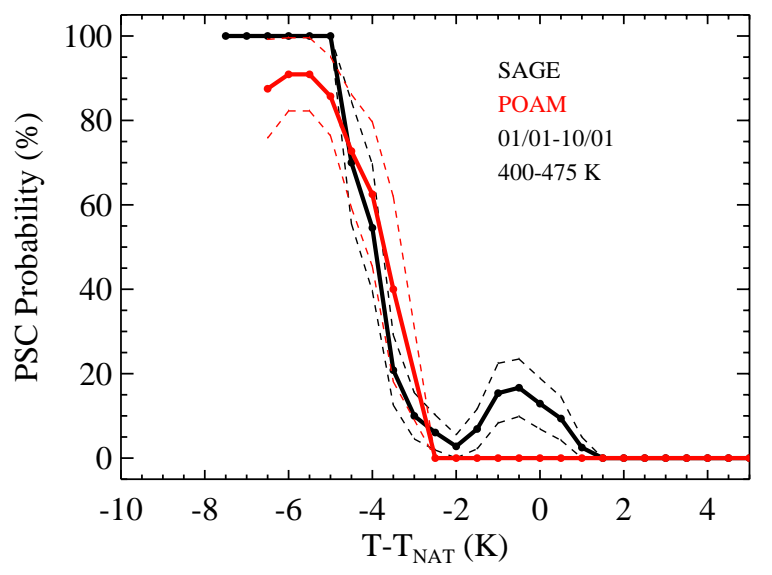

Fig. 7. PSC observation probability as a function of $\mathrm{T}_{\mathrm{NAT}}$ for both SAGE (black curve) and POAM (red curve), in the $400-475 \mathrm{~K}$ potential temperature level. The one-sigma level of uncertainty is shown in dashed lines. PSC probability is defined as the number of PSCs observed at a given temperature $( \pm 1 \mathrm{~K})$ divided by the total number of measurements at that temperature.

PSC observation probabilities agree to within $20 \%$ through the entire temperature range. The mode in the SAGE probability curve at $-2 \mathrm{~K}<\mathrm{T}_{\mathrm{NAT}}<1 \mathrm{~K}$ arises from PSCs detected by SAGE on 2 January when POAM operated only in the Southern Hemisphere and that PSCs detected by SAGE in this range were of small enhancement levels only slightly exceeding the 3-sigma PSC detection threshold. Small features in the POAM aerosol extinctions did not exceed the detection threshold. The better than $20 \%$ agreement gives confidence that our PSC detection approach is consistent across both instruments.

\subsection{PSC seasonal evolution}

In Fig. 8 we show all PSCs obtained in both the SAGE and POAM datasets during the 2002/2003 NH winter. The increased density of SAGE PSC observations is the result of the fact that SAGE retrievals are reported on a $0.5 \mathrm{~km}$ grid, while the POAM version 4 retrievals are reported on a $1.0 \mathrm{~km}$ grid. The red vertical bars in Fig. 8 denote the regions of the atmosphere, at the location of each measurement, which were saturated with respect to NAT. That is, regions in which $\mathrm{T}<\mathrm{T}_{\mathrm{NAT}}$. The blue vertical bars denote the regions where the air was saturated with respect to ice $\left(\mathrm{T}_{\mathrm{ICE}}\right)$. $\mathrm{T}_{\mathrm{NAT}}$ values shown in Fig. 8, and subsequent analyses were computed using POAM in-vortex monthly average water vapor measurements, obtained over the 2002/2003 NH winter, interpolated to a daily grid. The POAM water vapor measurements used in the calculation are not shown here, but are similar to those obtained for the 1999/2000 winter shown in Bevilacqua et al. (2002). For $\mathrm{HNO}_{3}$ mixing ratios, also needed in the $\mathrm{T}_{\mathrm{NAT}}$ calculation, we use the balloon-borne MARK IV (MKIV) measured profile obtained on 3 December 1999 from Kiruna 
Sweden (Coffey et al., 2003) with no time dependence. The MKIV instrument also made a measurement from Kiruna on 16 December 2002. However, in this study we have elected to use the 1999 measurement because denitrification was already evident in the 16 December 2002 measurement (Grooß et al., 2005). For reasons that will become clear in the next section, for the $\mathrm{T}_{\mathrm{NAT}}$ calculations used in this paper, it was important to use a polar, early winter $\mathrm{HNO}_{3}$ profile, before denitrification had occurred.

Overall, in the 2002/2003 NH winter PSCs were notably abundant. In fact, over the POAM data record, only in the 1999/2000 NH winter (SOLVE I) were more PSCs observed than in 2002/2003. However in the 1999/2000 winter, PSCs were observed extensively from mid-December through early February, and in late February through midMarch (Bevilacqua, et al., 2002), whereas-in the 2002/2003 winter, PSCs were primarily concentrated in the six-week period from early December through mid-January. POAM observed PSCs in 151 profiles from 14 November to 21 March. SAGE observed PSCs in 122 measurements from 15 November to 18 March. Both instruments observe PSCs almost daily throughout the month of December through the middle of January. This is consistent with Fig. 2, which shows temperatures well below $\mathrm{T}_{\mathrm{NAT}}$ throughout this period, and both POAM and SAGE sampling in the regions of the coldest air. Relatively few PSCs were observed by either instrument after mid-January. Figure 8 also shows the PSC altitudes tending to decrease from early December (where PSCs were observed by both SAGE and POAM at potential temperatures $>700 \mathrm{~K}$ ), through mid-January, coincident with the descent of sub- $\mathrm{T}_{\mathrm{NAT}}$ air. Poole et al. (2003) and Spang et al. (2005) also note the decrease of PSC altitude in December in both SAGE and Michelson Interferometer for Passive Atmospheric Sensing on board ENVISAT (MIPAS-E) measurements respectively. It is worth noting that instruments with very different measurement techniques gave consistent results in terms of PSC-height evolution. In early December PSCs were observed at potential temperatures below $500 \mathrm{~K}$ although ambient temperatures were above $\mathrm{T}_{\mathrm{NAT}}$. These low altitude PSCs were likely the result of early denitrification at higher altitudes which then precipitated $\mathrm{HNO}_{3}$ to lower altitudes. In the presence of early denitrification $\mathrm{HNO}_{3}$ concentrations would be elevated relative to the fixed profile used to calculate the NAT saturation temperature. MKIV measurements (Grooß et al., 2005) from 16 December 2002 suggest that denitrification $(\sim 4 \mathrm{ppbv}$ at $550 \mathrm{~K})$ had already occurred, and elevated nitric acid levels at $15 \mathrm{~km}$ were observed. Elevated nitric acid would raise the effective $\mathrm{T}_{\mathrm{NAT}}$. Beginning in late-December Fig. 8 also shows areas where the air is saturated with respect to NAT, yet few PSCs exist. This too is also likely a sign of denitrification as $\mathrm{HNO}_{3}$ depleted air would decrease $\mathrm{T}_{\mathrm{NAT}}$ as compared to its non-denitrified value.
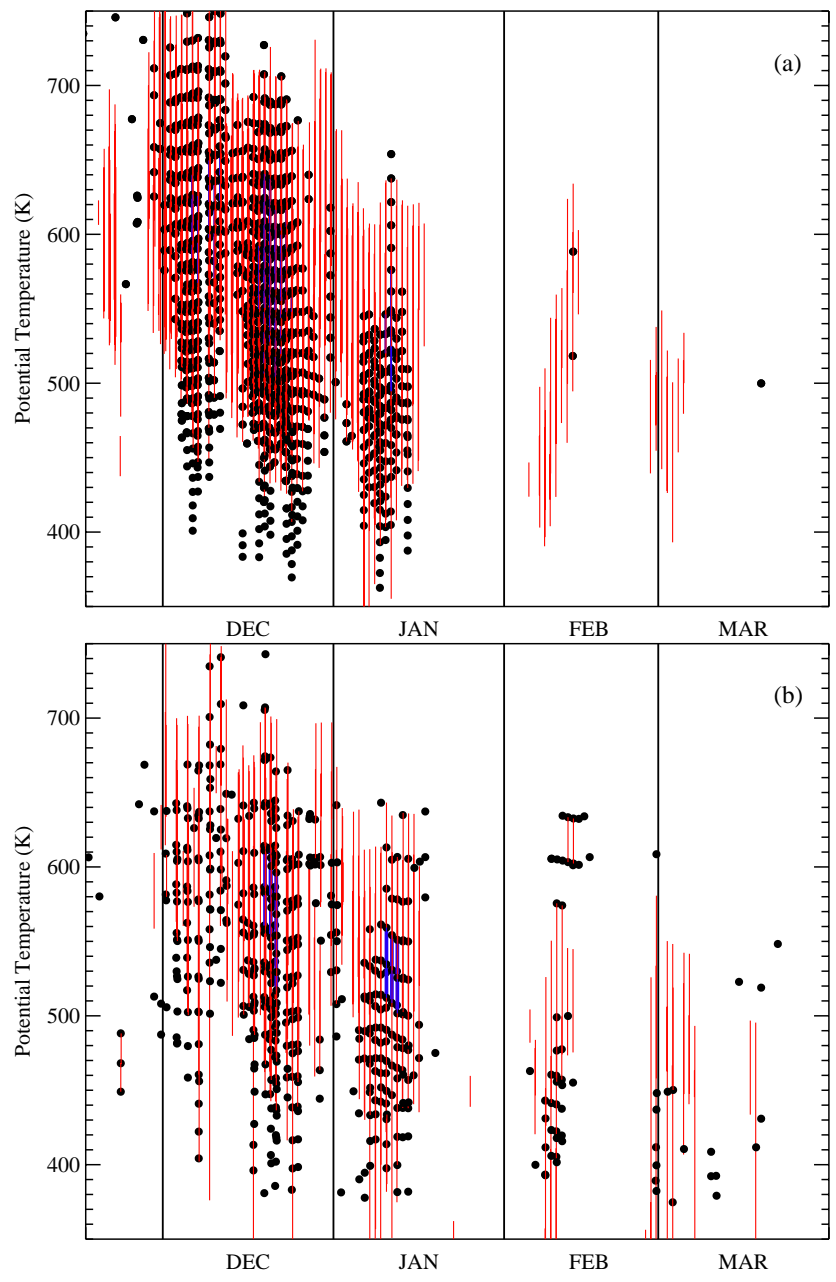

Fig. 8. The seasonal evolution of PSCs observed by (a) SAGE and (b) POAM plotted as a function of potential temperature and time over the 2002/2003 NH winter. Black dots denote the potential temperature and date of an observed PSC. Red vertical lines denote regions where the ambient air was saturated with respect to NAT. Blue vertical lines denote regions where the ambient air was saturated with respect to ice.

\subsection{PSC composition}

Strawa et al. (2002) use the relation between the extinction color ratio ( $1018 \mathrm{~nm}$ extinction/603 $\mathrm{nm}$ extinction) and the $1018 \mathrm{~nm}$ extinction to distinguish POAM observed PSC from the 1999/2000 NH winter among three categories, Type 1A (presumed to be solid crystalline in composition), type 1B (presumed to be small liquid droplets), and undetermined/mixed. This analysis has since been modified, by using the relation between the modified Ångström exponent and the $1018 \mathrm{~nm}$ extinction (Strawa et al., 2007 ${ }^{2}$ ). The new

\footnotetext{
${ }^{2}$ Strawa, A. W., Drdla, K., Fromm, M. D., et al.: Characteristics of Type I PSCs derived from POAM observations, in preparation, 2007.
} 
Table 1. Relative Change in PSC phase-type during the 2002/2003 winter. Type 1A and $1 \mathrm{~B}$ are as indicated, and mixed-phase and undetermined are labeled $1 \mathrm{M} / 1 \mathrm{U}$. The percentages shown are for the combined SAGE-POAM datasets.

\begin{tabular}{lllll}
\hline PSC Type & $1-10$ Dec & $11-20$ Dec & $21-30$ Dec & $1-10$ Jan \\
\hline $1 \mathrm{~A}$ & $31 \%$ & $51 \%$ & $70 \%$ & $46 \%$ \\
$1 \mathrm{~B}$ & $43 \%$ & $32 \%$ & $9 \%$ & $40 \%$ \\
$1 \mathrm{M} / 1 \mathrm{U}$ & $22 \%$ & $17 \%$ & $21 \%$ & $14 \%$ \\
\hline
\end{tabular}
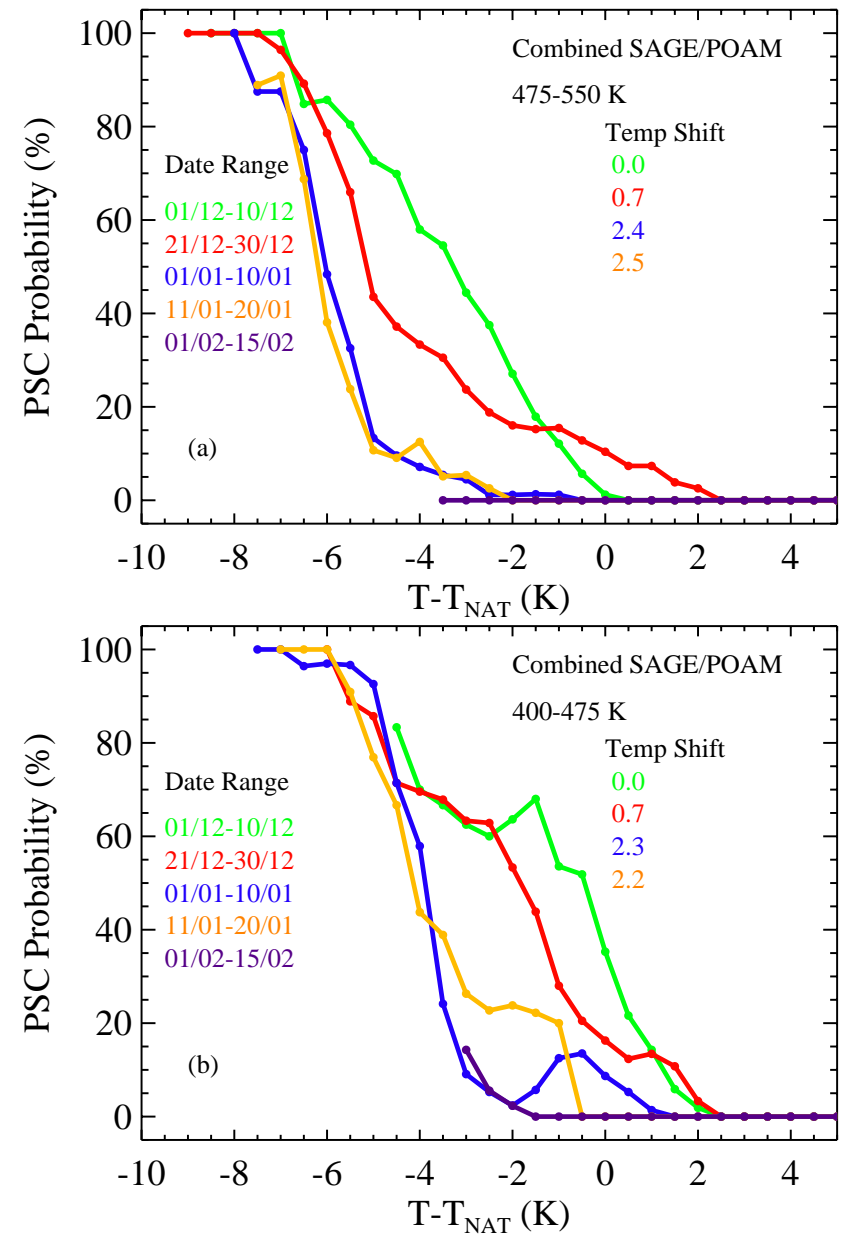

Fig. 9. The SAGE and POAM combined PSC observation probability as a function of T- $\mathrm{T}_{\mathrm{NAT}}$ for potential temperature ranges (a) 475-550 K and (b) 400-475 K. Five different time bins are shown, as indicated by the start day and end day in months and days. For these calculations the data were binned in two-Kelvin temperature bins and calculated on a half-Kelvin grid. PSC probability is defined as the number of PSCs in a bin divided by the total number of measurements in that bin. PSC probability is only shown for temperature bins containing a minimum of five measurements.

discrimination methodology has the advantage of using all of the POAM aerosol extinction channels rather than just two. The discrimination methodology takes advantage of the fact that Type 1A clouds are composed of a small number of large particles and Type 1B clouds are composed of a large number of small particles. As the PSCs grow, they bifurcate in extinction/Ångström-exponent space and can be distinguished as either Type 1A or 1B. As the cloud grows from the interstitial aerosol the extinction and Ångströmexponent are low and $1 \mathrm{~A}$ and $1 \mathrm{~B}$ clouds are indistinguishable from one another and the clouds are labeled undetermined (Type 1U). Clouds between the distinct 1A and 1B regions in extinction/Ångström-exponent space are labeled mixed-phase clouds (Type $1 \mathrm{M}$ ) and are presumably a combination of both NAT and STS particles. The new analysis has been applied to the 2002/2003 NH winter POAM PSC observations, and applied to SAGE observations as well. Table 1 summarizes the combined results for both SAGE and POAM for four ten-day periods throughout December and early January over the $400-550 \mathrm{~K}$ potential temperature range. In general, the results show that, among the PSCs that were unambiguously characterized, the fraction of Type 1A clouds increases throughout December to become the dominant PSC phase by the end of the month. At the same time, Type 1B clouds decrease dramatically in fractional abundance while the relative number of Type $1 \mathrm{U}$ and $1 \mathrm{M}$ clouds remains relatively constant. In early January the Type 1A clouds decrease in frequency while the Type 1B cloud frequency increases back to near the early December levels. The increase in frequency of Type 1A clouds throughout December is likely due to PSCs remaining cold for relatively long periods of time allowing for more growth of the particles. The increase in abundance of Type 1B clouds in January is possibly due to the fact that the air is highly denitrified. This would limit the amount of $\mathrm{HNO}_{3}$ available for uptake on cloud particles thus inhibiting their growth.

\section{PSC temperature relationship}

\subsection{PSC occurrence temperature: seasonal evolution}

As noted above, Fig. 8 also shows the region of air saturated with respect to NAT. In order to determine the NAT saturation temperature in this calculation we use time-varying water vapor mixing ratios obtained from POAM measurements. However, for $\mathrm{HNO}_{3}$ we use a fixed profile representative of 
early winter conditions. It can be readily seen that early in the first two weeks of December, PSCs are observed throughout the regions where the air is saturated with respect to $\mathrm{T}_{\mathrm{NAT}}$. However, in February and March when SAGE and POAM once again observe nominally NAT-saturated air, relatively few PSCs were observed.

To investigate PSC occurrence temperature and its evolution over the 2002/2003 winter in Figs. 9a and b we show the PSC observation probability as a function of temperature relative to $\mathrm{T}_{\mathrm{NAT}}$ (as described above in Sect. 3.1). In this analysis the data were binned in ten-day time periods beginning in early December, and the 400-475 K (Fig. 9a) and 475$550 \mathrm{~K}$ (Fig. 9b) potential temperature intervals (the 11-20 December time-period has been omitted as it is qualitatively similar to the 1-10 December time-period). These are both roughly $3 \mathrm{~km}$ increments ranging from approximately 16 to $22 \mathrm{~km}$. This represents the range in which a sufficient number of PSCs were observed, over a large part of the winter, for statistical significance. In the calculations depicted in Fig. 9 we have combined the POAM and SAGE observations. The data sets have been combined to increase the sampling size, and thus the statistical significance of the results, and to increase the coverage of the vortex relative to that obtained by either single instrument. The excellent agreement between the SAGE and POAM data sets illustrated in Figs. 5, 6 and (especially) 7 is taken here as justification for this approach.

There is a distinct shift to the left (lower temperatures) in the PSC occurrence-probability curves in both potential temperature intervals. In order to quantify this relative temperature shift, we have calculated the area between the PSC probability from the first time period (1-10 December), to each of the later time periods. Areas under the time-periods are calculated using a five-point Newton-Cotes (Press et al. 1992) formula. We consider this approach to yield a more accurate representation of PSC occurrence temperature shifts than the approach taken by Bevilacqua et al. (2002), in which we simply used the temperature at the $50 \%$ probability point, because it is averaged over all probabilities rather than one single value. The results of the temperature shift calculations are noted on Figs. 9a and b, and summarized in Table 3 (no temperature shift was calculated, in either potential temperature bin, for the February 1-15 time-bin because the probability never reaches a high enough level for a reasonable area to be calculated). We find a 2.2 to $2.5 \mathrm{~K}$ decrease in PSC occurrence temperature, relative to the NAT saturation temperature, between the beginning of December and the beginning of January. Although there was not a sufficient number of PSC observations to make statistically meaningful calculations of PSC occurrence temperatures in the early February and late February/ early March time periods when POAM again observed cold air, the few observations do suggest that the PSC occurrence temperature remained suppressed at the end of the vortex season.

There are potentially several scenarios which could account for this shift toward lower PSC occurrence temperature as the season progresses, relative to the NAT saturation temperature, illustrated in Fig. 10. These include: i) a change in the distribution of PSC composition (i.e. change in stable equilibrium temperatures of PSCs); ii) a time-varying bias in the MetOffice analysis used the $\mathrm{T}_{\mathrm{NAT}}$ computations; iii) irreversible dehydration and/or irreversible denitrification. Next we discuss each of these.

\subsubsection{Changes in PSC composition}

As discussed in Bevilacqua et al. (2002), under equivalent ambient conditions the Type 1B PSC formation temperature is approximately $4 \mathrm{~K}$ colder than the Type $1 \mathrm{~A}$ PSC formation temperature (Tabazadeh et al., 1994). This means that a change in the relative abundance of Type $1 \mathrm{~A}$ to $1 \mathrm{~B}$ clouds as the season progresses will change the PSC occurrence temperature relative to the NAT saturation temperature. In particular, an increase in the abundance of Type 1B clouds relative to Type 1A clouds will tend to decrease the occurrence temperature. Table 1 gives the relative abundance of Type 1A and $1 \mathrm{~B}$ clouds for four ten-day periods in early- mid- and late-December, and early-January for the 2002/2003 winter. Focusing on the early December and early January periods, as these exhibited the greatest temperature shift at all levels, these results suggest that the Type 1A/Type 1B ratio was higher in the later period than in early December and hence would not be the source of any shift in PSC occurrence temperature. However, there were a large amount of undetermined/mixed clouds in the early December period unaccounted for in the Type 1A/Type $1 \mathrm{~B}$ ratio. To assess the maximum extent to which the undetermined/mixed PSCs could change the PSC occurrence temperature we assume that the $22 \%$ undetermined/mixed clouds in early December behaved thermodynamically as Type 1A clouds and the $14 \%$ undetermined/mixed in the beginning of January behaved as Type 1B clouds. This limiting assumption implies a change in Type 1A/1B ratio from 53/47 in December to 46/54 in January. Assuming no Type 1A/1B bias in the POAM and SAGE data sets, this change in PSC composition would result in a $0.3 \mathrm{~K}$ lowering of the PSC occurrence temperature. Because it is relatively small compared to the greater than $2 \mathrm{~K}$ observed decrease in the net PSC occurrence temperature between early December and early January, we conclude that changes in PSC composition are unlikely to be responsible for the observed decrease. It is important to note that labeling PSCs as Type 1A or 1B does not definitively mean NAT or STS composition as the method is only able to differentiate particle size. Consequently PSCs labeled Type 1B may in fact be partly composed of small NAT PSCs, although Type 1A PSCs are unlikely to contain STS, as STS droplets are unlikely to grow to such large sizes. The implication of this is that the effective temperature of Type 1B PSCs is warmer than $\mathrm{T}_{\mathrm{STS}}$, thus the $0.3 \mathrm{~K}$ lowering of PSC occurrence temperature calculated above is likely an overestimate. 
Table 2. Change in PSC occurrence temperature over the 2002/2003 winter. PSC occurrence temperature is defined as the PSC observation probability as a function of temperature. Temperature shifts are relative to 1-10 December and indicate a shift to colder temperatures.

\begin{tabular}{lllll}
\hline $\begin{array}{l}\text { Potential Temperature } \\
\text { Range }\end{array}$ & $\begin{array}{l}\text { Temperature Shift }(\mathrm{K}) \\
1-10 \text { Dec }\end{array}$ & $\begin{array}{l}\text { Temperature Shift }(\mathrm{K}) \\
21-30 \text { Dec }\end{array}$ & $\begin{array}{l}\text { Temperature Shift (K) } \\
\text { 1-10 Jan }\end{array}$ & $\begin{array}{l}\text { Temperature Shift }(\mathrm{K}) \\
11-20 \text { Jan }\end{array}$ \\
\hline $400-475 \mathrm{~K}$ & 0 & 0.7 & 2.3 & 2.2 \\
$475-550 \mathrm{~K}$ & 0 & 0.7 & 2.4 & 2.5 \\
\hline
\end{tabular}

Table 3. MetOffice-GPS Temperature Comparison in the stratosphere during the 2002/2003 winter. Values shown are mean MetOffice-GPS and standard deviation. Numbers in parentheses correspond to the number of GPS profiles.

\begin{tabular}{lllll}
\hline $\begin{array}{l}\text { Pressure } \\
(\mathrm{hPa})\end{array}$ & $\begin{array}{l}1-10 \text { Dec } \\
(\mathrm{K})\end{array}$ & $\begin{array}{l}21-30 \text { Dec } \\
(\mathrm{K})\end{array}$ & $\begin{array}{l}1-10 \text { Jan } \\
(\mathrm{K})\end{array}$ & $\begin{array}{l}11-20 \text { Jan } \\
(\mathrm{K})\end{array}$ \\
\hline 50 & $-0.32 \pm 1.1(78)$ & $0.66 \pm 1.3(177)$ & $0.43 \pm 1.1(162)$ & $0.89 \pm 1.5(105)$ \\
70 & $-0.27 \pm 0.85(66)$ & $0.14 \pm 1.1(123)$ & $-0.03 \pm 0.8(109)$ & $0.32 \pm 1.2(93)$ \\
\hline
\end{tabular}

\subsubsection{Possible biases in MetOffice analysis}

In order to test for possible changes in the biases of the MetOffic temperatures over the measurement period we have conducted extensive comparisons between MetOffice temperatures and Challenging Mini-Satellite Payload (CHAMP) Global Positioning System (GPS) radio occultation (Wang et al., 2004) version 005 temperatures. The GPS temperatures are an independent measurement, which are non-reliant on apriori measurements below $30 \mathrm{~km}$ and have been extensively validated (Wickert et al., 2004). Table 2 summarizes the temperature bias for each of the five predefined time periods at the $70 \mathrm{hPa}(\sim 17 \mathrm{~km})$ and $50 \mathrm{hPa}(\sim 20 \mathrm{~km})$. This analysis suggests the MetOffice temperatures become biased warm with respect to the CHAMP temperature measurements by $1.2 \mathrm{~K}$ and $0.6 \mathrm{~K}$ at the 50 and $70 \mathrm{hPa}$ levels respectively. The small warming in the model temperature bias still lies within the one standard-deviation level of significance. An increase in the warm bias of the MetOffice temperatures would have the effect of PSC probabilities increasing at warmer temperature as the season progresses, thus it is unlikely that the calculated decrease in PSC occurrence temperatures can be attributed to a time-varying bias in temperature.

\subsubsection{Irreversible dehydration}

NAT saturation temperature is highly dependent upon water vapor mixing ratio. As such, irreversible dehydration would have a significant effect in lowering $\mathrm{T}_{\mathrm{NAT}}$. Irreversible dehydration occurs when ice clouds form and the ice crystals sediment out. It should be noted that the calculation of $\mathrm{T}_{\mathrm{NAT}}$ uses the POAM water vapor, which would account for any large-scale dehydration, but an analysis of POAM water vapor measurements did not detect dehydration within the noise level of the measurements (not shown). Analyses of the Fast In Situ Hygrometer (FISH) water vapor measurements also showed no signature of dehydration up to $20 \mathrm{~km}$ (Stroh et al., 2005). Figure 3 suggests that on a few days in December, temperatures were below $\mathrm{T}_{\mathrm{ICE}}$, thus there exists a possibility that dehydration was a factor in decreasing the PSC observation probability as the season progressed. POAM aerosol extinction profiles exhibit a phenomenon known as a HiZmin in the presence of an ice PSC (Fromm et al., 1997). A HiZmin occurs when the air becomes sufficiently opaque in the presence of ice that a measurement profile terminates at an abnormally high altitude. In the 2002/2003 NH winter none were observed. SAGE did not observe any HiZmin profiles either, however, Poole et al. (2003) show three measurements between 1-10 December and three more between 11-20 December that appear to be ice PSCs. The fact that POAM did not unambiguously observe ice-PSCs, and that SAGE conducted only six measurements on two separate days that may have observed ice-PSCs, suggests that if they were present, they would only have existed for a short period of time before the growth of large ice crystals could occur and sediment out of the atmosphere. Nedoluha et al. (2002) show evidence of air parcels below ice saturation temperatures and supersaturated for greater than two days with no clear evidence of dehydration. Schiller et al. (2002) show evidence of local dehydration at levels of $0.5 \mathrm{ppmv}$ in the $\mathrm{NH}$ during the 1999/2000 winter. Meteorological conditions for the formation of ice PSCs in the 1999/2000 winter were more favorable than for the 2002/2003 winter. On a vortex wide scale, in 1999/2000 temperatures were observed below TICE on a daily basis for three weeks in late December and early January (see Fig. 2, Bevilacqua, et al., 2002). Figure 3 does not suggest such a sustained, uninterrupted, time with temperatures below $\mathrm{T}_{\text {ice }}$, thus, even had dehydration occurred during 
Table 4. Combined SAGE/POAM inferred denitrification over the 2002/2003 winter.

\begin{tabular}{lllll}
\hline $\begin{array}{l}\text { Potential Temperature } \\
\text { Range }\end{array}$ & $\begin{array}{l}\text { Denitrification }(\%) \\
\text { 1-10 Dec }\end{array}$ & $\begin{array}{l}\text { Denitrification }(\%) \\
21-30 \text { Dec }\end{array}$ & $\begin{array}{l}\text { Denitrification }(\%) \\
\text { 1-10 Jan }\end{array}$ & $\begin{array}{l}\text { Denitrification }(\%) \\
11-20 \text { Jan }\end{array}$ \\
\hline $400-475 \mathrm{~K}$ & 0 & 38 & 80 & 78 \\
$475-550 \mathrm{~K}$ & 0 & 38 & 82 & 82 \\
\hline
\end{tabular}

the 2002/2003 winter, dehydration levels would likely be less than those observed by Schiller et al. (2002) in 1999/2000. If dehydration did occur, the maximum amount of decrease in water vapor would have been $0.5 \mathrm{ppmv}$. This small level of dehydration would result in a maximum decrease of the NAT saturation temperature of $0.4 \mathrm{~K}$, which is less than the random error in the temperature measurements. We conclude that dehydration had little to no effect on the shift of PSC occurrence temperature.

\subsection{Inferring denitrification}

Having largely eliminated all other possible scenarios to explain the observed greater than $2 \mathrm{~K}$ shift in PSC occurrence temperatures between early December and early January, we conclude that this shift is most likely a manifestation of irreversible denitrification. This conclusion was also reached for the 1999/2000 winter by Bevilacqua et al. (2002). Here we follow up by estimating the amount of irreversible denitrification that would be required to cause the observed shifts in PSC occurrence temperature. We invert the Hanson and Mauersburger (1988) formulation assuming a constant water vapor mixing ratio in order to determine the amount of $\mathrm{HNO}_{3}$ mixing ratio change required to produce changes in the NAT saturation temperature equal to the net PSC occurrence temperature changes listed in Table 3 . The results of these calculations are shown in Table 4 . We find that in order to attribute the observed decreases in the net PSC occurrence temperature to decreases in $\mathrm{T}_{\mathrm{NAT}}$ resulting from denitrification would require $\mathrm{HNO}_{3}$ decreases of nearly $80 \%$ between early December and early January. If we assume an upper bound of a $0.4 \mathrm{~K}$ uncertainty in the temperature shifts due to unaccounted impacts from the factors listed in Sect. 4.1, this results in a 7-10\% uncertainty in the inferred denitrification. Denitrification likely maximized at the end of December, as seen from Table 1 this is when 70\% of PSCs were of Type 1A. As pointed out above, the evidence suggests that PSC occurrence temperature remained low through the remainder of the winter. This, in turn, suggests that vortex remained denitrified at the levels found in early January through early March.

It should be noted that a limitation of the methodology is the requirement of several measurements - both PSC and non-PSC - over a broad temperature range to infer denitrification. In order to obtain a statistically significant sample with an adequate range of temperatures, we have found it necessary to use all solar occultation measurements within the vortex over a period of $\sim 10$ days. This yields a vortex average of denitrification with no information on the spatial distribution within the vortex.

Davies et al. (2006) use the Denitrification by Lagrangian Particle Sedimentation (DLAPSE) model during the 2002/2003 winter and compare these results with gasphase observations of $\mathrm{HNO}_{3}$ and $\mathrm{N}_{2} \mathrm{O}$ the MIPAS-E. Analyses of the MIPAS-E measurements show that denitrification reached levels of $80 \%$ at the core of the polar vortex in early January with less denitrification near the vortex edge $\left(65^{\circ}-\right.$ $70^{\circ} \mathrm{N}$ equivalent latitude). Because the value of $80 \%$ inferred above is a vortex average this suggests that it is likely an overestimate when compared with the MIPAS-E measurements. Analyses of in situ measurements of $\mathrm{N}_{2} \mathrm{O}$ and $\mathrm{NO}_{\mathrm{y}}$ from the High Altitude Gas AnalyseR (HAGAR) and SIOUX instruments show levels of denitrification near 50\% (Voigt et al., 2005; Grooß et al., 2005).

The levels of denitrification inferred above agree well with those from the MIPAS-E measurements, but exceed those made from the in situ HAGAR and SIOUX measurements. Agreement is expected to be better with the MIPAS-E results as those are direct gas-phase $\mathrm{HNO}_{3}$ measurements rather than $\mathrm{NO}_{\mathrm{y}}$ measurements. The methodology is dependent upon the gas-phase $\mathrm{HNO}_{3}$ to determine $\mathrm{T}_{\mathrm{NAT}}$ and any consequent changes in $\mathrm{T}_{\mathrm{NAT}}$. Bevilacqua et al. (2002) also showed good agreement from their inferred levels of denitrification with in-situ measurements during the 1999/2000 winter. Repeating the technique outlined above with the POAM data from 1999/2000 produces results which are consistent with those of Bevilacqua et al. (2002), with inferred levels of denitrification between 75 and $80 \%$ at both the 16-18 and 19$21 \mathrm{~km}$ regions.

The levels of denitrification inferred for the 2002/2003 winter slightly exceed those inferred during the 1999/2000 winter, yet the 1999/2000 winter experienced lower temperatures, and experienced temperatures below $\mathrm{T}_{\mathrm{NAT}}$ for a longer period of time, than that of 2002/2003. However, the month of December 2002, when most of the denitrification occurred, was particularly unique in that temperatures early in the season were cold at a broad altitude range. This may have allowed NAT particles to descend to much lower altitudes than in 1999/2000, thus permanently denitrifying a thicker layer than in that year and thereby producing a larger temperature shift in our $75 \mathrm{~K}$ layer PSC statistics. 


\section{Summary and conclusions}

We have presented an overview of PSC measurements made by SAGE III and POAM III during the 2002/2003 NH winter. Throughout the SOLVE II/VINTERSOL winter SAGE observed PSCs in 122 one-micron aerosol extinction profiles, while POAM observed PSCs in 151 profiles. PSCs were first unambiguously observed on 15 November 2002 with SAGE and 14 November 2002 with POAM. PSCs were observed extensively, and on a near-daily basis, from the end of November to 15 January. After 4 February 2003, PSCs were again observed, but less frequently than the December/January time period. The last PSC observed by SAGE was on 18 March 2003, and the last observed by POAM was on 21 March 2003. In early December PSCs were observed at potential temperatures from roughly $375 \mathrm{~K}$ to $750 \mathrm{~K}$. Throughout December the top of this range decreases to near $600 \mathrm{~K}$. In February and March, PSC observations were primarily constrained to potential temperatures below $500 \mathrm{~K}$.

We have also shown good agreement using the unification PSC detection methodology (Fromm et al., 2003) between SAGE and POAM. Extinction measurements at PSC levels of enhancement agree well qualitatively between the two instruments. PSC occurrence as a function of ambient temperature from SAGE and POAM agree well with one another.

We have calculated the PSC probability as a function of temperature. We conclude that variations in PSC probability are a result of irreversible denitrification. Denitrification occurred extensively throughout the month of December and into mid-January. We infer that the stratospheric air was irreversibly denitrified by $\sim 80 \%$ by early January in both the $400-475$ and $475-550 \mathrm{~K}$ potential temperature regimes. The lower stratosphere likely remained denitrified through early-March. Most of the denitrification occurred in late December, when the preponderance of PSCs was Type 1A. The levels of inferred denitrification are in good agreement with MIPAS-E $\mathrm{HNO}_{3}$ and $\mathrm{NO}_{2}$ measurements near the core of the polar vortex but exceed the levels of denitrification made by HAGAR and SIOUX instruments.

The refinement of the methodology of inferring denitrification from PSC observations from solar occultation measurements can serve as a valuable tool to estimate levels of denitrification using other platforms such as SAM II, SAGE I and SAGE II. Keeping in mind the spatial and temporal limitations discussed in Sect. 4.2 this could yield valuable longterm estimates of Arctic denitrification, and should be pursued.

Acknowledgements. This work was supported by the NASA data purchase project and the NASA SOSST project. SAGE III and POAM III data were obtained from the NASA Langley Research Center Atmospheric Sciences Data Center. MetOffice data were obtained from the NASA Goddard Space Flight Center. CHAMP temperature profiles were obtained from the GeoForschungsZentrum Information System and Data Center. We thank two anonymous referees for their comments and suggestions to improve this paper.

Edited by: R. MacKenzie

\section{References}

Bevilacqua, R. M., Fromm, M. D., Alfred, J. M., Hornstein, J., Nedoluha, G. E., Hoppel, K. W., Lumpe, J. D., Randall, C. E., Shettle, E. P., Browell, E. V., Butler, C., Dörnbrack, A., and Strawa, A. W.: Observations and analysis of polar stratospheric clouds detected by POAM III during the 1999/2000 Northern Hemisphere winter, J. Geophys. Res., 107(D20), 8281, doi:10.1029/2001JD000477, 2002.

Bevington, P. R. and Robinson, D. K.: Data Reduction and Error Analysis for the Physical Sciences, McGraw-Hill, New York, 1992.

Browell, E. V., Ismail, S., Carter, A. F., Higdon, N. S., Butler, C. F., Robinette, P. A., Toon, O. B., Schoeberl, M. R., and Tuck, A. F.: Airborne lidar observations in the wintertime Arctic Stratosphere: Polar stratosphere clouds, Geophys. Res. Lett., 17(4), 385-388, 1990.

Carslaw, K., Luo, B. P., Clegg, S. L., Peter, Th., Brimblecombe, P., and Crutzen, P. J.: Stratospheric aerosol growth and $\mathrm{HNO}_{3}$ gas phase depletion from coupled $\mathrm{HNO}_{3}$ and water uptake by liquid particles, Geophys. Res. Lett., 21(23), 2479-2482, 1994.

Coffey, M. T., Mankin, W. G., Hannigan, J. W., and Toon, G. C.: Airborne spectroscopic observations of chlorine activation and denitrification of the 1999/2000 winter Arctic stratosphere during SOLVE, J. Geophys. Res., 107, 8303, doi:10.1029/2001JD001085, 2002 (printed 108(D5), 2003).

Davies, S., Mann, G. W., Carslaw, K. S., Chipperfield, M. P., Remedios, J. J., Allen, G., Waterfall, A. M., Spang, R., and Toon, G. C.: Testing our understanding of Arctic denitrification using MIPAS-E satellite measurements in winter 2002/2003, Atmos. Chem. Phys., 6, 3149-3161, 2006, http://www.atmos-chem-phys.net/6/3149/2006/.

Fahey, D. W., Gao, R.-S., Carslaw, K. S., et al.: The detection of large $\mathrm{HNO}_{3}$-containing particles in the winter Arctic stratosphere and their role in denitrification, Science, 291, 1026-1031, 2001.

Fromm, M. D., Lumpe, J. D., Bevilacqua, R. M., Shettle, E. P., Hornstein, J., Massie, S. T., and Fricke, K. H.: Observations of Antarctic polar stratospheric clouds by POAM II: 1994-1996, J. Geophys. Res.,102, 23 659-23 672, 1997.

Fromm, M. D., Bevilacqua, R. M., Hornstein, J., Shettle, E. P., Hoppel, K., and Lumpe, J. D.: An analysis of POAM II Arctic polar stratospheric cloud observations, 1993-1996, J. Geophys. Res., 104, 24 341-24 357, 1999.

Fromm, M. D., Alfred, J., and Pitts, M.: A unified, long-term, highlatitude stratospheric aerosol and cloud database using SAM II, SAGE II, and POAM II/III data: Algorithm description, database definition, and climatology, J. Geophys. Res., 108(D12), 4355, doi:10.1029/2002JD002772, 2003.

Grooß, J.-U., Günther, G., Müller, R., Konopka, P., Bausch, S., Schlager, H., Voigt, C., Volk, C. M., and Toon, G. C.: Simulation of denitrification and ozone loss for the Arctic winter 2002/2003, Atmos. Chem. Phys., 5, 1437-1448, 2005, http://www.atmos-chem-phys.net/5/1437/2005/. 
Hanson, D. and Mauersberger, K.: Laboratory studies of the nitric acid trihydrate: Implications for the south polar stratosphere, Geophys. Res. Lett., 15, 855-858, 1988.

Lucke, R. L., Korwan, D. R., Bevilacqua, R. M., et al.: The Polar Ozone and Aerosol Measurement (POAM) III instrument and early validation results, J. Geophys. Res., 104(D15), $18785-$ $18799,1999$.

Manney, G. L., Krüger, K., Sabutis, J. L., Sena, S. A., and Pawson, S.: The remarkable 2003-2004 winter and other recent warm winters in the Arctic stratosphere since the late 1990s, J. Geophys. Res., 110, D04107, doi:10.1029/2004JD005367, 2005.

NASA Langley Research Center, SAGE III algorithm theoretical basis document: Solar and lunar algorithm, Rep. LaRC 475-00109, Vers. 2.1, Hampton Va., 2002.

Nash, E. R., Newman, P. A., Rosenfield, J. E., and Schoeberl, M. R.: An objective determination of the polar vortex using Ertel's potential vorticity, J. Geophys. Res., 101, 9471-9478, 1996.

Naujokat, B. and Grunow, K.: The stratospheric arctic winter 2002/03: Balloon flight planning by trajectory calculations. Proceedings of the 16th ESA Symposium on European Rocket and Balloon Programmes and Related Research, St. Gallen, May 2003, ESA SP-530, Switzerland, 421-425, 2003.

Nedoluha, G. E., Bevilacqua, R. M., and Hoppel, K. W.: POAM measurements of water vapor in the Arctic and Antarctic, J. Geophys. Res., 107, doi:10.1029/2001JD001184, 2002.

Poole, L. R. and McCormick, M. P.: Polar stratospheric clouds and the Antarctic Ozone hole, J. Geophys. Res., 93(D7), 8423-8430, doi:10.1029/88JD00106, 1988.

Poole, L. R. and Pitts, M. C.: Polar stratospheric cloud climatology based on Stratospheric Aerosol Measurement II observations from 1978 to 1989, J. Geophys. Res., 99, 13 083-13 089, 1994.

Poole, L. R., Trepte, C. R., Harvey, V. L., Toon, G. C., and VanValkenburg, R. L.: SAGE III observations of Arctic polar stratospheric clouds - December 2002, Geophys. Res. Lett., 30(23), 2216, doi:10.1029/2003GL018496, 2003.

Press, W. H., Teukolsky, S. A., Vetterling, W. T., and Flannery, B. P.: Numerical Recipes in C: The Art of Scientific Computing, Second Edition, Cambridge University Press, 1992.

Russell, P., Livingston, J., Schmid, B., Eilers, J., Kolyer, R., Redemann, J., Ramirez, S., Yee, J.-H., Swartz, W., Shetter, R., Trepte, C., Risley Jr., A., Wenny, B., Zawodny, J., Chu, W., Pitts, M., Lumpe, J., Fromm, M., Randall, C., Hoppel, K., and Bevilacqua, R.: Aerosol optical depth measurements by airborne sun photometer in SOLVE II: Comparisons to SAGE III, POAM III and airborne spectrometer measurements, Atmos. Chem. Phys., 5, 1311-1339, 2005, http://www.atmos-chem-phys.net/5/1311/2005/.

Schiller, C., Bauer, R., Cairo, F., Deshler, T., Dörnbrack, A., Elkins, J., Engel, A., Flentje, H., Larsen, N., Levin, I., Müller, M., Oltmans, S., Ovarlez, J., Schreiner, J., Stroh, F., Voigt, C., and Vömel, H.: Dehydration in the Arctic stratosphere during the THESEO2000/SOLVE campaigns, J. Geophys. Res., 107(D20), 8293, doi:1029/2001JD000463, 2002.
Spang, R., Remedios, J. J., Kramer, L. J., Poole, L. R., Fromm, M. D., Müller, M., Baumgarten, G., and Konopka, P.: Polar stratospheric cloud observations by MIPAS on ENVISAT: detection method, validation and analysis of the northern hemisphere winter 2002/2003, Atmos. Chem. Phys., 5, 679-692, 2005,

http://www.atmos-chem-phys.net/5/679/2005/.

Strawa, A. W., Drdla, K., Fromm, M., Pueschel, P. F., Hoppel, K. W., Browell, E. V., Hostetler, C. A., and Hamill, P.: Discriminating Type Ia and Ib Polar Stratospheric Clouds in POAM satellite data, J. Geophys. Res., 107(D20), 8291, doi:10.1029/2001JD000458, 2002.

Stroh, F., and the EUPLEX Science Team: European Polar Stratospheric Cloud and Lee Wave Experiment (EUPLEX), Final Report of the EU project EVK2-CT-2001-00119, 2005.

Swinbank, R. and O'Neill, A.: A stratosphere-troposphere data assimilation system, Mon. Wea. Rev., 122, 686-602, 1994.

Tabazadeh, A., Turco, R. P., Drdla, K., Jacobson, M. Z., and Toon, O. B.: A study of Type I polar stratospheric cloud formation, Geophys. Res. Lett., 21, 1619-1622, 1994.

Tabazadeh, A., Santee, M. L., Danilin, M. Y., Pumphrey, H. C., Newman, P. A., Hamill, P. J., and Mergenthaler, J. L.: Quantifying denitrification and its effect on ozone recovery, Science, 288, 1407-1411, 2000.

Thomason, L. W. and Taha, G.: SAGE III aerosol extinction measurements: Initial results, Geophys. Res. Lett., 30(12),1631, doi:10.1029/2003GL017317, 2003.

Thomason, L. W., Poole, L. R., and Randall, C. E.: SAGE III aerosol extinction validation in the Arctic winter: comparisons with SAGE II and POAM III, Atmos. Chem. Phys., 7, 14231433, 2007, http://www.atmos-chem-phys.net/7/1423/2007/.

Voigt, C., Schlager, H., Luo, B. P., Dörnbrack, A., Roiger, A., Stock, P., Curtius, J., Vössing, H., Borrmann, S., Davies, S., Konopka, P., Schiller, C., Shur, G., and Peter, T.: Nitric Acid Trihydrate (NAT) formation at low NAT supersaturation in Polar Stratospheric Clouds (PSCs), Atmos. Chem. Phys., 5, 13711380, 2005, http://www.atmos-chem-phys.net/5/1371/2005/.

Wang, D., Stiller, G. P., Clarmann, T., Fischer, H., López-Puertas, M., Funke, B., Glatthor, N., Grabowski, U., Höpfner, M., Kellman, S., Kiefer, M., Linden, A., Tsidu, G. M., Milz, M., Steck, T., Jiang, J., Ao, C., Manney, G., Hocke, K., Wu, D. L., Romans, L. J., Wickert, J., and Schmidt, T.: Cross-validation of MIPAS/ENVISAT and GPS-RO/CHAMP temperature profiles, J. Geophys. Res., 109, D19311, doi:10.1029/2004JD004963, 2004.

Wickert, J., Schmidt, T., Beyerle, G., König, R., Reigber, C., and Jakowski, N.: The Radio Occultation Experiment aboard CHAMP: Operational Data Analysis and Validation of Vertical Atmospheric Profiles, J. Meteorol. Soc. Jap., 82(1B), 381-395, 2004. 